\title{
PAULO FREIRE: EDUCADOR POPULAR REVOLUCIONÁRIO HOJE
}

\author{
PAULO FREIRE: REVOLUTIONARY POPULAR EDUCATOR \\ TODAY
}

\section{PAULO FREIRE: EDUCADOR POPULAR REVOLUCIONARIO HOY}

Tovar Nelson Pereira Junior ${ }^{1}$

${ }^{1}$ Escola Municipal Mercia do Nascimento, Rede Municipal de Ensino de Ilhabela, Ilhabela, São Paulo - Brasil. E-mail: tvrniu@gmail.com

\begin{abstract}
Resumo
No espírito das justas homenagens prestadas ao educador Paulo Freire em virtude do centésimo aniversário de seu nascimento, este ensaio busca enfatizar certas peculiaridades de seu pensamento educacional popular revolucionário, ao mesmo tempo em que se esforça por produzir uma conexão de tal pensamento com os desafios impostos pelo atual momento histórico brasileiro. Para tanto, serve-se, sobretudo, dos registros de uma experiência em processo de que se constitui a obra Cartas a GuinéBissau (1977). No itinerário reflexivo, tentam-se evidenciar: o caráter romântico-revolucionário do pensamento freiriano, o papel teórico-metodológico da articulação entre prática social e educação e, derivada disso, uma sofisticada concepção educacional que se faz revolucionária, justo por aprofundar-se na realidade concreta, entendida como processo portador de tendências "inéditosviáveis" a serem desenvolvidas no sentido da superação da sociedade dividida em classes. Tais conclusões de índole teórica, no entanto, não são encaradas no ensaio como encerradas em si mesmas, mas extraem seu sentido, e mesmo coerência, em relação à obra tematizada por poderem funcionar como ato rememorativo, no qual as lutas do passado podem se conectar explosivamente com as lutas do presente.
\end{abstract}

Palavras-chave: Revolução. Realidade. Educação. Popular. Capitalismo.

\begin{abstract}
In the spirit of the righteous tribute paid to educator Paulo Freire, on account of the hundredth anniversary of his birth, this essay seeks to emphasize certain peculiarities of his revolutionary popular educational thought while striving to produce a connection of such thought with the challenges posed by the current Brazilian historical moment. Therefore, it uses the records of an experience in the process of which the work Cartas a GuinéBissau (1977) is constituted. In the reflective itinerary, it was attempted to highlight: the romantic-revolutionary character of freirian thought; the theoretical-methodological role of the articulation between social practice and education and, derived from this, a sophisticated
\end{abstract}


educational conception that becomes revolutionary, precisely because it goes deeper into the concrete reality, understood as a process that carries trends to be developed towards the overcoming of a society divided into classes. Such theoretical conclusions, however, are not seen in the essay as they are closed in themselves, but it extracts their meaning and coherence about the thematized work, as they can function as a remembrance act, in which the struggles of the past can be connected explosively with the struggles of the present.

Keywords: Revolution. Reality. Education. Popular. Capitalism.

\section{Resumen}

En el contexto de homenajes al educador Paulo Freire, consecuencia del centésimo cumpleaños de su nacimiento, este ensayo busca enfatizar determinadas peculiaridades de su pensamiento educaional popular revolucionario, al mismo tiempo en que pone esfuerzo por producir conexión de dicho pensamiento en relación a los desafios puestos por el presente momento histórico brasileño. En este sentido, utiliza, sobretodo, los registros de una experiencia en desarrollo de que se constituye la obra Cartas a Guiné-Bissau (1977). En el itinerario reflexivo, se intentan tornar evidentes: la dimensión romántico-revolucionaria del pensamiento freiriano, el papel teórico-metodológico de la articulación entre práctica social y educación y, derivado de esto, una sofisticada concepción educacional que se hace revolucionaria, justo por la profundización en la realidad concreta, comprendida como proceso en el que se descubren tendencias "inéditos-viables, a partir de las cuales se puede superar la sociedad dividida en clases. Dichas conclusiones de caracter teórico, sin embargo, no funcionan en el ensayo como cerradas en si mismas, pero extraen su sentido, e incluso coerência, con relación a la obra tematizada, una vez que funcionan como acto rememorativo, en el cual las luchas del pasado se pueden conectar explosivamente con las luchas del presente.

Palabras clave: Revolución. Realidade. Educación. Popular. Capitalismo.

\section{Palavras necessárias}

Não são os cem anos de nascimento do grande educador Paulo Freire o que mais nos impele a escrever sobre sua obra incontornável, mas o fato de que o centésimo aniversário de seu nascimento coincida com um momento histórico no qual sua obra se converte num instrumento imprescindível para pensarmos, coletivamente, ações de superação de um tipo de sociedade que tem sabido renovar incessantemente suas formas de opressão.

Compartilhamos, por isso, a ideia de que se constitui uma contradição abordar o pensamento de Paulo Freire de um modo puramente encomiástico. A pura louvação, desprovida do caráter crítico, não é capaz de produzir consequências no sentido da transformação da sociedade dividida em classes, inibidora de nossa "ontológica vocação de ser mais”. E qualquer leitura cuidadosa das obras de Freire é o bastante para que se constate

que todo seu esforço girou no sentido de produzir uma práxis, no âmbito educacional, que 
pudesse servir aos processos de transformação da sociedade antidemocrática, herdeira da violência colonial, bem como da lógica cega do modo de produção capitalista.

Se a mera desqualificação pretende esterilizar Freire por um lado, por outro, a pura louvação, pretendendo contribuir, acaba por tornar estéril seu legado, na medida em que o reduz a puro objeto de contemplação.

Nosso objetivo neste ensaio, o qual busca articular-se com outros textos que formam este dossiê em justa homenagem aos cem anos de nascimento de Paulo Freire, é, superando a louvação, converter-se em oportunidade de reflexão, tanto quanto possível rigorosa, sobre alguns aspectos de uma obra atual, "atualizável”, reflexão que não poderá ser feita sem que, ao mesmo tempo, tematizemos a realidade concreta que nos desafia, hoje, em tempos de crises superpostas.

\section{Introdução}

Rios de tinta foram derramados na tentativa de se realçarem os múltiplos aspectos que constituem a obra de Paulo Freire. Trata-se, de fato, de uma obra de muitas dimensões que veio a se tornar um marco incontornável para se pensar a educação - e não só a popular - no século XX.

Caso, no entanto, queiramos nos socorrer do próprio autor para refletir sobre uma dimensão fundante de sua contribuição teórica - a qual permanece não só válida como necessária aos que apostamos num mundo-outro -, poderíamos evocar uma passagem cujo conteúdo se repete em mais de uma ocasião em seus escritos e inúmeros testemunhos orais:

\footnotetext{
Até hoje, sem exceção, nenhum dos poucos livros que escrevi deixou de ser uma espécie de relatório, não burocrático, é certo, de experiências realizadas ou realizando-se e momentos distintos da atividade político-pedagógica em que me acho engajado desde o começo da juventude. (FREIRE, 1977, p. 173)
}

Por meio dessa avaliação sintética e de conjunto realizada na década de 1970 podemos surpreender o fundamento, o "espírito" mesmo da filosofia da educação de Paulo Freire. Nela, a reflexão, vale dizer, a teoria, funciona como momento de apreensão intelectiva da ação educacional concreta, na qual ele, enquanto educador, toma parte ativa. 
Para que possamos, no entanto, captar o sentido profundo, o real sentido, poderíamos dizer, dessa reflexão, fruto de uma prática educacional em curso, é necessário que evidenciemos o fato de que tais experiências tomadas como objeto de reflexão são experiências educacionais postas a serviço de processos de transformação radical da sociedade burguesa. Ou seja, a ação educacional freiriana, na qual se articulam dialeticamente a dimensão teórica e a prática, é uma ação revolucionária.

Nesse sentido, é ilustrativa a observação que Freire faz em sua carta de aceitação ao convite de colaboração com o Conselho Mundial de Igrejas: "Vocês devem saber que tomei uma decisão. Meu problema é o problema dos esfarrapados da Terra. Vocês precisam saber que optei pela revolução" (GADOTTI, 1996, p. 163).

Ação revolucionária educacional que, por outro lado, compreende seu papel específico num processo de transformação estrutural da sociedade.

Freire, sendo um educador revolucionário, não é um educador revolucionário idealista (pelo menos a partir de fins da década de 1960). Ele compreende com clareza que, na relação entre sociedade e educação, a educação cumpre um papel de reprodução de certos valores hegemônicos essenciais a dada sociedade. A transformação radical da sociedade burguesa, portanto - na qual a educação joga um papel importante -, deve incidir sobre a estrutura mesma da sociedade, em seu modo de produção material da vida e em sua estrutura política. Ou seja, “...não é a educação que forma a sociedade de uma certa maneira, mas a sociedade que, formando-se de uma certa maneira, constitui a educação de acordo com os valores que a norteiam" (FREIRE, 2007, p. 173).

E ele prossegue, na mesma obra Ação Cultural para a Liberdade, a partir de uma visão não mecanicista, mas dialética: "Mas, como este não é um processo mecânico, a sociedade, que estrutura a educação em função dos interesses de quem tem o poder, passa a ter nela um fator fundamental de sua preservação" (FREIRE, 1977. p. 173).

Até aqui, neste texto em que buscamos salientar o aspecto revolucionário do pensamento educacional freiriano, importa retermos o seguinte: 1) um aspecto fundante do pensamento freiriano é o fato de que tal reflexão se faz a partir de uma experiência educacional prática em curso; 2) tal experiência educacional prática, a partir da qual o pensamento de Freire se exerce, é de caráter revolucionário, na medida em que busca servir ao objetivo geral de transformação radical da sociedade regida pelo modo de produção capitalista. 
A fim de esboçarmos de modo justo um primeiro quadro do pensamento educacional de Paulo Freire ressaltando sua dimensão não idealista e revolucionária, será importante acrescentarmos um terceiro aspecto a esses dois anteriormente citados: 3) se o pensamento freiriano tem na prática o seu fundamento e se essa prática tem uma índole transformadora radical, por outro lado é imprescindível levarmos em consideração que o sujeito dessa ação educacional para a libertação, o sujeito exclusivo dessa ação não é ele mesmo, o educador Paulo Freire, mas o povo oprimido com o qual ele produz uma educação libertadora no encontro. Melhor dito: é enquanto alguém que se identifica com o ponto de vista dos esfarrapados do mundo, dos vencidos, em processo de libertação que Freire se faz sujeito, participando como educador-educando desse mesmo processo. Quer dizer, é aprendendo do povo que participa ativamente do processo de sua libertação que o educador Paulo Freire pôde se converter em educador revolucionário; melhor: em um educador popular revolucionário.

\section{A experiência africana}

Uma forma de sermos consequentes, hoje, com a teoria educacional freiriana talvez seja evocando a poderosa experiência educacional que se abriu para e com Paulo Freire na África, na época de seu exílio, na década de 1970.

Evocar esses eventos significa um verdadeiro ato de rememoração, no espírito da filosofia da história de Walter Benjamin. Evocar a experiência libertadora dos países africanos em relação ao jugo colonialista significa contarmos a história a partir do ponto de vista dos vencidos. Para repetir a já tão citada, mas ainda atual e bela expressão de Benjamin: evocar a experiência emancipadora africana da década de 1970 é escovar a história a contrapelo.

Nesse sentido, evocar essa experiência, no atual cenário, é produzir mais do que simples memória. É quando, no tempo-do-agora, em nosso caso brasileiro de 2021, tempo de tragédias superpostas, de encurtamento e embaçamento de horizontes, aproveitamos o que poderia ser um texto-ornamento de uma comemoração em torno dos cem anos de nascimento de um educador famoso, e fazemos disso um ato vivo, a partir do passado que pode ser criado, dinamizado, conectado explosivamente com o agora. Tempo feito de densidades, não linear, aberto, no qual o passado, sobretudo aquele das lutas que não se esgotaram em sua força transformadora, pode fecundar de algum modo o presente, ainda que, é claro, tenhamos que nos valer das possibilidades desse momento histórico concreto que é o nosso, pois, "em 
história se faz o que historicamente é possível e não o que se gostaria de fazer" (FREIRE, 2007, p. 174).

É por isso que nosso texto será um Jano bifronte, em dois sentidos: 1) quando falarmos em Freire, estaremos falando do Freire-que-é-sendo-com-os-oprimidos-e-seu-tempo-histórico; 2) quando falarmos sobre a experiência africana, na qual Freire tomou parte como educadoreducando-revolucionário, fa-lo-emos enquanto ato de conexão, desse passado elétrico dinamizado, com nosso presente em movimento, em busca de superação de suas contradições.

Dito de outro modo, estaremos em pleno exercício de falar de e com Freire enquanto espécie de vocalizador atravessado pelas vozes dos explorados que se rebelaram, sendo, concomitantemente, nós mesmos que escrevemos, atravessados pelas dores de justa indignação que hoje vão ganhando corpo e, quiçá, certo contorno de unidade, para a luta de transformação a que almejamos.

\subsection{Cartas a Guiné-Bissau}

Se a experiência africana de Paulo Freire e o pensamento que se desenvolveu como um dos momentos dessa experiência podem ser destacados como momentos exemplares de sua militância educacional popular revolucionária, o conjunto de textos intitulado Cartas a Guiné-Bissau: registros de uma experiência em processo (1977) pode ser tido como momento reflexivo exemplar dessa sua fase africana.

Essa obra, como indica o próprio título, tenta captar com certo fôlego a dinamicidade, a cadência viva da experiência prática de um educador com o povo que se exercita em seu processo de emancipação das estruturas coloniais-burguesas rumo a um arranjo estrutural socialista.

Acreditamos que uma tal experiência, riquíssima em múltiplos aspectos, seja metodologicamente interessante para pensarmo-nos pensando-a, uma vez que nos permite captar o espírito mesmo da filosofia educacional freiriana. Experiência em processo que talvez nos inspire na criativa descoberta de "inéditos viáveis", os quais não brotam espontaneamente, mas requerem uma leitura de mundo engajada capaz de apreender não só o que está aí, empiricamente evidente, mas também as tendências que não surgem senão no contexto de um certo espírito profético, também necessário em assuntos de revolução. 
Em suma, Cartas a Guiné-Bissau se nos afigura como uma obra que nos impede, por sua força dinâmica, de cairmos na tentação do fatalismo que acomete tantos de nossos contemporâneos que perderam a fé na transformação da sociedade pelo fato de que a transformação radical da sociedade parece, hoje, mais distante do que nunca.

Além disso, é uma das obras, em virtude da realidade concreta de que ela nasce, na qual se nos oferece, em sua máxima expressão, a vitalidade do pensamento revolucionário de Paulo Freire. Pensamento que, julgamos, seja hoje necessário de ser criativamente revisitado, também, pelo fato de encontrarmos certa domesticação burguesa-idealista desse autor tão celebrado quanto pouco estudado, como, aliás, sói acontecer com outros clássicos.

Por último: justo porque a realidade de reconstrução nacional rumo ao socialismo - na qual se deu a experiência de educação popular de Freire em Guiné-Bissau - é radicalmente distinta daquela de destruição nacional rumo ao fascismo em que vivemos hoje no Brasil, o exercício de pensarmo-nos, pensando essa obra, dá-se como algo instigante, para não dizer necessário.

Em vez de justificarmos, portanto, a adoção do espírito dessa obra como balizador de nosso texto, em virtude de sua afinidade com o espírito de nossa época, vamos no sentido contrário, justificando a necessidade do espírito da obra por causa de seu antagonismo com o que caracteriza nosso momento histórico "rebaixado".

Mas não é justamente a vigência do rebaixamento de nossa época, prenhe de atrocidades, o que torna ainda mais necessário o espírito das épocas em que a utopia da transformação se fez carne?

\section{Alguns instantâneos da experiência educacional de Paulo Freire em Guiné-Bissau e na Tanzânia}

Em Cartas a Guiné-Bissau: registro de uma experiência em processo, Freire nos dá conta de que seu primeiro contato com a África não se fez mediante a visita a Guiné-Bissau, mas a partir da Tanzânia. 
O breve, mas denso, "molhado", relato que faz sobre sua visita àquele país é significativo a fim de surpreendermos certa dimensão peculiar de seu pensamento popular revolucionário. Vejamos:

\begin{abstract}
(...) na medida em que, deixando o aeroporto de Dar es Salaam, há cinco anos passados, em direção ao 'campus' da universidade, atravessava a cidade, ela ia se desdobrando ante mim como algo que eu revia e em que me reencontrava. Daquele momento em diante, as mais mínimas coisas - velhas conhecidas - começaram a falar a mim, de mim. A cor do céu, o verde-azul do mar, os coqueiros, as mangueiras, os cajueiros, o perfume de suas flores, o cheiro da terra; as bananas, entre elas a minha bem amada banana-maçã; o peixe ao leite de coco; os gafanhotos pulando na grama rasteira; o gingar do corpo das gentes andando nas ruas, seu sorriso disponível à vida; os tambores soando no fundo das noites; os corpos bailando e, ao fazê-lo, 'desenhando o mundo', a presença, entre as massas populares, da expressão de sua cultura que os colonizadores não conseguiram matar, por mais que se esforçassem para fazê-lo, tudo isso me tomou todo e me fez perceber que eu era mais africano do que pensava. (FREIRE, 1977, p. 14-15. Grifo nosso.)
\end{abstract}

O sociólogo marxista franco-brasileiro Michael Lowy aborda o romantismo como uma visão de mundo anticapitalista específica. Juntamente com Robert Sayre (1992), ele propõe uma superação da concepção redutora do romantismo como apenas uma escola literária, artística ou filosófica.

Tal visão de mundo pode ser sintetizada como uma reação à modernidade capitalista caracterizada por uma valorização de aspectos do passado pré-capitalista. É nesse sentido que se poderia compreender a valorização da Idade Média por parte dos artistas do período romântico. No entanto, a valorização da Idade Média por parte de escritores, pensadores e artistas desse período é somente um dos modos de se reagir à modernidade e está longe de ser o único.

Ressaltemos ainda que Lowy e Sayre (1992) propõem uma tipologia das diversas visões de mundo românticas, que iriam desde uma atitude conservadora até uma atitude romântico-revolucionária, se pensarmos tais visões de mundo a partir de seu viés político. Nesse último caso - da perspectiva romântico-revolucionária -, diferentemente daquele - da perspectiva conservadora -, o retorno ao passado pré-capitalista não significaria uma atitude passadista, por meio da qual se proporia um retorno capaz de restituir o mundo àquilo que fora anteriormente à modernidade. Funcionaria muito mais como "um desvio no passado apontado para o futuro". Quer dizer, o passado pré-capitalista, ainda não atingido pelos "males" da modernidade (o espírito de cálculo, o desencantamento do mundo, a racionalidade instrumental, a dominação burocrática), funcionaria como inspiração para a superação da 
modernidade rumo a uma sociedade utópica, ainda não localizada historicamente, uma sociedade nova, comunitária, orgânica, na qual o valor de uso superasse os valores de troca e, portanto, a lógica da mercantilização universal.

Acreditamos, por uma série de motivos, que não teremos oportunidade de desenvolver suficientemente neste ensaio que o pensamento de Paulo Freire poderia ser considerado romântico-revolucionário.

Acontece somente que esse lugar e esse tempo anterior ao capitalismo que the serviriam como inspiração não seriam a Idade Média ou mesmo a Antiguidade, mas o tempo e o espaço da potência da cultura popular, capaz, inclusive, de resistir à tentativa de seu assassinato, por parte dos colonizadores, tal como consta no trecho em análise.

Seja na África, seja no Nordeste brasileiro ou no Chile, Paulo Freire será muito sensível à força da cultura popular, a partir da qual ele extrairá os elementos de uma educação rebelde, capaz de servir aos projetos de transformação, de libertação das amarras do mundo moderno mecanizado, domesticador, impedidor do "ser mais", próprio do humano.

Ressaltemos ainda que encarar o viés romântico revolucionário do anticapitalismo de Freire não é algo importante pelo fato de conquistarmos mais uma etiqueta para adornar a já tão celebrada teoria freiriana, mas para que seja ressaltado um elemento a mais de ressonância entre a perspectiva freiriana e as lutas contemporâneas que se desdobram na América Latina, por exemplo, as quais funcionam como poderosas vias de superação da destrutividade da sociedade da mercadoria e que, na avaliação de Lowy, possuem, algumas delas (como a luta dos povos originários), um viés romântico. Ou seja, para que a partir dessas afinidades estejamos sensíveis para que a educação libertadora possa seguir compondo com os movimentos de emancipação em curso no mundo contemporâneo. Por outro lado, a fim de que a própria perspectiva libertadora freiriana seja cada vez mais fecundada por essas afinidades de luta.

Nesse sentido, a perspectiva romântico-revolucionária de Paulo Freire, estribada na força da cultura popular que resiste à voracidade padronizadora da cultura moderna do progresso, e apontada para a construção de uma sociedade nova, se junta, enquanto ação cultural para a libertação, a outras expressões da luta anticapitalista: a causa dos povos originários, dos negros hiperexplorados da periferia das grandes cidades, dos trabalhadores e trabalhadoras do campo, além da histórica luta de militantes cristãos na América Latina. 
Pois bem, o excerto transcrito que dá conta da recordação de Freire sobre seu reencontro com a África, a partir da Tanzânia, parece-nos ilustrativo desse aspecto romântico da perspectiva revolucionária de Paulo Freire, aspecto que comparece em sua estadia na África, mas que, de algum modo, atravessa todo o itinerário de sua militância educacional.

\subsection{O educador como político e artista}

Ademais de um românico-revolucionário, Freire faz parte daquele grupo de intelectuais criadores de um marxismo heterodoxo que não se reduziu ao marxismo das cartilhas oficiais: mecanicista, economiscista, determinista.

Paulo Freire se impregnou da corrente quente do marxismo (para usarmos um termo de Ernst Bloch), ou seja, aquela corrente para a qual a paixão revolucionária nunca poderia se reduzir à frieza do cálculo científico. Não é que Freire abrisse mão do rigor metodológico e conceitual, mas, em sua concepção, esse deveria servir àquela paixão, até para que tivesse sentido de ser. É nesse sentido que vamos encontrar passagens significativas como essa: "Na verdade, o educador é um político e um artista, que se serve da ciência e das técnicas, jamais um técnico friamente neutro" (FREIRE, 1977, p. 34).

Ser um político e um artista aqui equivale a ser capaz de entrar em ressonância profunda com a paixão da transformação, o ponto de vista dos esfarrapados do mundo, no mais das vezes oriunda do sofrimento da condição desumanizadora, a fim de se criarem vias de superação dessa condição, superação que não pode prescindir das armas da crítica que são forjadas, em grande medida, com os recursos científicos.

Se, por um lado, não podemos abrir mão do rigor científico que nos permite, por exemplo, ler de modo crítico o mundo - e sem o que ele não pode ser transformado -, por outro lado o exercício de sua leitura só faz sentido se há no horizonte o desejo e, mesmo, o sentimento da necessidade de sua transformação. A ciência deve, portanto, estar a serviço da paixão revolucionária.

\subsection{A articulação fundamental entre prática social e educação}


Conforme salientamos no início deste ensaio, e como é de conhecimento de qualquer leitor minimamente atento das obras de Paulo Freire, a relação entre prática e teoria, ação e reflexão é uma tônica de seu pensamento. Pensamento dialético por excelência. Em Cartas $e$ Guiné-Bissau (FREIRE, 1977), isso aparece de modo quase obsessivo. E, se trazemos esse traço da abordagem de Freire em Guiné-Bissau, é porque estamos convencidos de que ele seja um componente significativo para nossas lutas atuais.

Compartilhemos algumas notas que sirvam como subsídio para nossos comentários:

A alfabetização de adultos, como a educação em geral, não pode superpor-se à prática social que se dá numa certa sociedade, mas, ao contrário, deve emergir desta prática, enquanto uma de suas dimensões. (FREIRE, 1977, p. 34)

A questão fundamental que se colocava, pois, não era a de se fazer a alfabetização de adultos por ela mesma ou a de fazê-la como se fosse ela, em si, um instrumento de transformação da realidade, mas a de pô-la a serviço da reconstrução nacional. (FREIRE, 1977, p. 34)

Servindo-se desta ou daquela experiência no campo de uma cooperativa de produção, os militantes, envolvidos nos projetos de alfabetização, como animadores, deveriam estar atentos a como relacionar tais experiências com a alfabetização. (FREIRE, 1977, p. 35)

Tal preocupação, à primeira vista excessiva, é compreensível, dado o contexto em que Freire atua: contexto de "reconstrução nacional", a partir de uma luta de libertação que havia obtido êxito, num primeiro momento - o da expulsão dos colonizadores. Mas a luta revolucionária dependia de muitos e complexos fatores a fim de atingir o triunfo verdadeiro que era a transição de uma sociedade organizada em torno do modo de produção capitalista, herdado do colonizador, para uma sociedade organizada em bases socialistas, que deveria ser criada com a ativa participação popular.

Consequente com tal desafio e ciente da gravidade do momento é que Freire, ao lado dos companheiros do Instituto de Ação Cultural (IDAC), do Comissário de Educação e Cultura Mário Cabral e em profunda sintonia com os animadores de círculos de cultura atuantes em regiões diversamente engajadas no projeto de reconstrução nacional, irá propor programas de alfabetização de adultos, encarado como ação cultural para a liberdade.

Constatamos, portanto, que a insistência de Freire, em Cartas a Guiné-Bissau (1977), pela apreensão da realidade concreta - somente a partir do que seria possível a proposição de programas educacionais na área da alfabetização de adultos - revela não somente uma postura 
ética, mas uma metodologia de trabalho, imprescindível para o êxito avaliado em termos de colaboração coerente com o novo projeto de sociedade em curso, no qual se incluía como condição de sua realização, a efetiva participação popular.

De qualquer modo, é do chão da prática social concreta, multifacetada, que se deve derivar a aposta no âmbito educacional, de modo que essa mesma prática social possa receber a colaboração educacional libertadora. Dito de outro modo: não há possibilidade de que uma educação que se quer transformadora seja feita fora do âmbito da prática social, de que a educação é um dos momentos. E, para que se possa derivar uma proposta educacional da prática social, é fundamental que essa leitura da realidade seja apreendida, tanto quanto possível, em sua complexidade real.

Partindo, portanto, da importância metodológica da leitura da realidade para a elaboração de propostas de intervenção educacional que sirvam a processos revolucionários, enfatizemos que tal leitura, para ser válida, não pode ser uma leitura idealista, que mais oculta do que desvela a realidade, visto que a inventa em vez de a reproduzir reflexivamente, motivo pelo qual é fundamental o uso das ciências (políticas, sociológicas, econômicas, históricas etc.), não em si mesmas, mas como momento analítico a partir do que se fará a síntese que nos permitirá sair das meras impressões empíricas da realidade, fruto de nosso contato imediato com o mundo, em direção a uma mais fidedigna apreensão do real concreto, ou, em direção à "reprodução ideal do movimento real do objeto", segundo Marx.

Lembrando: realidade entendida enquanto totalidade dinâmica na qual suas múltiplas dimensões se articulam dialeticamente. Totalidade criada historicamente pela humanidade (em interação com a natureza), mas que, ao mesmo tempo, determina objetivamente suas possibilidades de ação. E por último: realidade que coloca determinações ao ser da humanidade, mas somente a partir da qual sua transformação é possível.

Se, portanto, é compreensível a ênfase dada por Freire à articulação da educação com a realidade social, que necessitava ser lida de modo rigoroso, a fim de se derivar uma colaboração consequente com o processo de reconstrução nacional, em pleno contexto revolucionário, talvez pudéssemos dizer que ainda mais importância hoje deve ser dada a tal articulação, uma vez que nosso contexto é o de uma revolução de índole fascista em curso. Precisamos, portanto, nas lutas do momento, ter uma lúcida leitura da realidade, de modo a produzirmos as ações possíveis no sentido de uma revolução ecossocialista (LOWY, 2014) e, com isso, fazer funcionar um tipo de educação que responda a esse contexto em disputa. 


\title{
3.3 A realidade e suas possibilidades ou a atualidade dos inéditos viáveis
}

Interessa-nos agora, em mais essa cena do trabalho educacional popular revolucionário de Freire em Guiné-Bissau, acompanhar o modo como ele pensou a experiência concreta de que participava como colaborador - no âmbito da alfabetização de adultos - do processo de reconstrução nacional daquele país recém-saído da luta de libertação colonial.

Acreditamos, pelos motivos que tentaremos demonstrar, que isso será instrutivo, uma vez mais, para pensarmos nossos desafios no Brasil contemporâneo.

Seja o seguinte trecho a balizar nossos comentários:

\begin{abstract}
Na verdade, o que marca a 'linha de massas', o que a define como tal, é o seu antielitismo revolucionário, o seu antipaternalismo, é o papel de sujeitos que devem as massas populares nela assumir, através de sua ingerência na própria programação da campanha. E o dinamismo dialético entre tática e estratégia em que ela sempre se encontra. Estrategicamente, constantemente voltada para a generalização à globalidade da sociedade em que se processa; taticamente, porém, podendo partir, não da totalidade, se as condições objetivas e subjetivas não o permitem, mas daquelas áreas em que estas condições já se estão dando ou se acham prestes a darse. Se as condições já estão dadas ou em parte dadas, o esforço de alfabetização corre rapidamente; se as condições estão prestes a dar-se, aquele esforço ajuda a sua concretização. Se as condições não existem e estão muito longe de existir, a alfabetização carece de sentido. Por isso é que não há como confundir a 'linha de massas' com a generalização voluntarista da alfabetização. (FREIRE. 1977:64. Grifo nosso.)
\end{abstract}

O trecho em questão, entre outras coisas, permite-nos apreender algo fundamental, resultante, justamente, da importância conferida por Freire à articulação entre prática social e propostas de intervenção educacional libertadora. Qual seja: a consciência de que existem determinadas condições necessárias para que o trabalho educacional libertador seja exitoso e, nisso, o discernimento de que tais condições se apresentam de modo diverso em cada área onde se pretenda uma ação cultural libertadora, dada a complexidade do real, já mencionada anteriormente. 
Esse é um dado evidenciador do refinamento, do nível de diferenciação alcançado por Freire enquanto leitor de realidades, das quais se encharcava ${ }^{1}$ e de que dependia sua contribuição enquanto intelectual militante.

Aqui será apropriado um comentário: a realidade não pode ser concebida somente como o que estávaí, oferecendo-se à nossa experiência imediata no mundo, mas é feita também de tendências. A captação de tais tendências não desenvolvidas, em vias de se desenvolver ou bloqueadas pela lógica de funcionamento atual da sociedade, é justo o âmbito no qual deveremos atuar enquanto militantes, realistas, da utopia. Mas tais tendências, a fim de serem captadas, requerem, não uma leitura superficial, idealista, feita segundo certa mentalidade cotidiana mediana da realidade, mas uma leitura, digamos com Freire, profética, informada pelos recursos analíticos da ciência. Ou seja, não é a leitura da realidade o que pode redundar em desânimo para as lutas de transformação, mas uma leitura superficial, que reduz a realidade àquilo que nossa experiência imediata pode apreender.

Vejamos: uma vez que nossa experiência imediata tende a reproduzir certas concepções estereotipadas de mundo, e na medida em que tais estereotipias são, no mais das vezes, resultantes da ideologia hegemônica, em nosso caso aquela liberal, idealista, burguesa, isso significa que, caso reduzamos nossa concepção de realidade àquilo que recolhemos de nossa experiência imediata no mundo, estaremos, inconscientemente, reproduzindo a ideologia hegemônica, para a qual o capitalismo é o reflexo da própria natureza humana, sistema no qual, inclusive, se dá o "fim da história". Ou seja, algo imutável. Daí o fatalismo em que muitos caem, sob a alegação de que, afinal, "compreenderam” a realidade.

Nesse caso, segundo nos parece, o que ocorre em verdade é que tais pessoas, justamente, deixaram de compreender a realidade. Tal compreensão seria possível caso se aprofundassem e amadurecessem, na prática, sua perspectiva revolucionária, para além do momento inicial de "empolgação". Isso porque são os revolucionários os que se comprometem radicalmente com a verdade da realidade, a fim de transformá-la, ao passo que a ideologia burguesa se interessa e se esmera em seu mascaramento, a fim de se perpetuar enquanto classe dominante.

\footnotetext{
${ }^{1}$ Vale lembrar aqui que tal articulação pode ser acusada no pensamento freiriano, desde aquela que pode ser considerada sua primeira obra de fôlego: Educação e atualidade brasileira (2003). Tal obra foi apresentada como requisito para concurso público na então Universidade do Recife (atual Universidade Federal de Pernambuco [UFPE]) em 1959. É óbvio que tal leitura de realidade, ao longo dos anos, sofrerá significativa inflexão, entre outras coisas, pela incorporação de categorias analíticas marxistas ao seu trabalho intelectual.
} 
A diferenciação, portanto, não voluntarista, apresentada por Freire, é capaz de funcionar como alternativa ao fatalismo, na medida em que está alicerçada na realidade ${ }^{2}$, a qual descobrimos como algo multifacetado, processual, na qual se escondem tendências que podem ser exploradas no sentido de superação do atual estado do ser social, determinado, mas não "fatalizado", pela lógica de funcionamento do capitalismo.

Observemos que no trecho em análise Freire menciona áreas em que a alfabetização de adultos se desenvolvia celeremente, em virtude de as condições das práticas sociais específicas necessárias estarem preenchidas, e outras em que o esforço educacional poderia se efetivar, no caso de as condições estarem em vias de se dar, mas também ele menciona áreas em que o esforço alfabetizador teria poucas chances de êxito, dado que tal ação educacional careceria de sentido em virtude da ausência de condições, situação em que o esforço educacional não poderia aparecer como algo necessário.

O importante de ser retido da diferenciação freiriana acerca das condições que comparecem de modo diverso em cada área onde se pretendam intervenções educacionais libertadoras é que nos cabe ter tato para tal forma de atuação educacional. Quer dizer, para atuar no nível dos "inéditos viáveis", não basta a vontade, que pode redundar em voluntarismo, mas é necessário também um conhecimento associado, claro, a uma dose de intuição (profetismo) para percebermos o nível de amadurecimento das condições que podem permitir o êxito da ação educacional libertadora.

São esses inéditos viáveis, os quais, por vezes, não coincidem com aquilo que idealizamos, que escapam daqueles que, partindo de uma postura idealista-ingênua, acabam se deslocando para uma atitude fatalista.

Para nós, brasileiros deste conturbado início de século XXI, em plena hegemonia e crise do modo de produção capitalista, época de transição e de crises superpostas em vários âmbitos, nessa época também de ascensão das direitas de índole fascista, período em que vivemos verdadeiras situações-limite, acompanhar o pensamento de Paulo Freire nessa diferenciação é, em grande medida, uma necessidade.

Em Ação Cultural para a Liberdade (FREIRE, 2007, p. 173-4), nosso autor equaciona a questão nos seguintes termos:

\footnotetext{
${ }^{2}$ Para uma discussão acerca das maiores ou menores possibilidades de apreensão da realidade, a partir do ponto de vista ou do observatório em que nos postamos para abordá-la, conferir o clássico As aventuras de Karl Marx contra o Barão de Munchhausen: marxismo e positivismo na sociologia do conhecimento, de Michael Lowy (1998)
} 
O fato, por exemplo, de que determinadas circunstâncias históricas em que se encontra o educador não lhe permitam participar, mais ativamente, deste ou daquele aspecto constitutivo do processo de transformação revolucionária de sua sociedade, não invalida um esforço menor, em que esteja engajado, desde que este seja o esforço que lhe é historicamente viável.

Em história se faz o que historicamente é possível e não o que se gostaria de fazer.

Freire, inclusive, anos depois de haver regressado ao Brasil, na década de 1990, em plena ascensão neoliberal na América Latina, quando se iniciava de modo decisivo o cumprimento das diretrizes do Consenso de Washington, em plena hegemonia capitalista depois da dissolução da União Soviética, deu mostras dessa maturidade revolucionária, agindo na medida da viabilidade histórica.

\section{Considerações finais}

Percorremos um itinerário no intuito de evidenciar o caráter revolucionário do pensamento educacional de Paulo Freire, partindo de uma obra que se configura como uma experiência em processo. Experiência de colaboração, no âmbito educacional, com o processo de reconstrução nacional, o qual se desdobrava depois de uma vitoriosa luta de libertação de um país africano da secular condição de colônia europeia.

Tal esforço de escrita, no entanto, conforme salientamos, não foi feito segundo um mero impulso hermenêutico como forma de pura interpretação verbalista do pensamento de um clássico da educação do século XX cujo centenário de nascimento se completa nesse conturbado ano de 2021.

Nosso esforço, que significa, sim, uma justa homenagem a um educador popular revolucionário, encontra sua justificação em um motivo, acreditamos, eminentemente freiriano: o de, partindo da prática, carregada de justa indignação num cenário de um processo revolucionário de índole fascista, tentarmos refletir sobre um traço da obra de um autor comprometido com a transformação das estruturas de injustiça da sociedade burguesa, a fim de retornarmos a essa mesma prática, transformando-a, no encontro com outras e outros que também compartilham das situações-limite na qual nos encontramos, mais ou menos desafiados.

Mas sentimo-nos também desafiados, e isso esteve sempre presente como motivação na escrita deste texto, pela apropriação domesticadora que se vem fazendo do pensamento 
freiriano, seja por pura ingenuidade ou pela astúcia liberal, não menos perversa do que a grotesca ação das ultradireitas conservadoras.

Seja, portanto, este ensaio, articulado com os outros textos deste dossiê, um lugar de comunhão no qual, mediatizados pelo mundo, pronunciemos palavras de ação libertadora. Venceremos!

\section{Referências}

FREIRE, Paulo. Ação Cultural para a Liberdade. 12a edição. São Paulo: Paz e Terra, 2007 Cartas à Guiné-Bissau: registros de uma experiência em processo. Rio de Janeiro: Paz e Terra, 1977.

Freire, 2003.

Educação e Atualidade Brasileira. 3 ed. São Paulo: Cortez ; Instituto Paulo

GADOTTI, Moacir (org.). Paulo Freire: uma biobibliografia. São Paulo: Cortez: Instituto Paulo Freire; Brasília, DF; UNESCO, 1996.

LOWY. Michael. Walter Benjamin: aviso de incêndio: uma leitura das teses "Sobre o conceito de história", São Paulo: Boitempo, 2005.

LOWY, Michael; SAYRE, Robert. Revolta e Melancolia: o romantismo na contracorrente da modernidade. São Paulo: Boitempo, 2015.

STRECK, Danilo; REDIN, Euclides; ZITKOSKI, José. (orgs.). Dicionário Paulo Freire. 2 ed, Belo Horizonte: Autêntica Editora, 2010.

Recebido em: 16/08/2021

Aprovado em: 19/09/2021

Publicado em 29/10/2021 